\title{
Barriers in Latin America for the management of locally advanced breast cancer
}

\author{
Joseph A Pinto', Luis Pinillos ${ }^{2}$, Cynthia Villarreal-Garza ${ }^{3}$, Zaida Morante ${ }^{4,5}$, Manuel V Villarán ${ }^{1}$, Gerson Mejía ${ }^{6}$, Christian \\ Caglevic $^{7,8}$, Alfredo Aguilar ${ }^{4}$, Williams Fajardo ${ }^{9}$, Franz Usuga ${ }^{10}$, Marcia Carrasco ${ }^{11,12}$, Pamela Rebaza ${ }^{12}$, Ana M Posada ${ }^{12}$, Indira \\ Tirado-Hurtado ${ }^{1}$, Claudio Flores ${ }^{1}$ and Carlos S Vallejos ${ }^{4}$
}

\author{
${ }^{1}$ Unidad de Investigación Básica y Traslacional, Oncosalud-AUNA, Lima 15036, Peru \\ ${ }^{2}$ Departamento de Radioterapia, Oncosalud-AUNA, Lima 15036, Peru \\ ${ }^{3}$ Departamento de Investigación y de Tumores Mamarios, Instituto Nacional de Cancerología, Mexico City 14080 , Mexico \\ ${ }^{4}$ Departamento de Medicina Oncológica, Oncosalud-AUNA, Lima 15036, Peru \\ ${ }^{5}$ Departamento de Oncología Médica, Instituto Nacional de Enfermedades Neoplásicas, Lima 15038, Peru \\ ${ }^{6}$ Departamento de Oncología Médica, Hospital Clínico Viedma, Cochabamba 00725, Bolivia \\ ${ }^{7}$ Medical Oncology Department, Clinica Alemana, Santiago 5951, Chile \\ ${ }^{8}$ Facultad de Medicina Clínica Alemana, Universidad del Desarrollo, Santiago 700, Chile \\ 9Departamento de Medicina Especializada, Hospital Nacional Dos de Mayo, Lima 15003, Peru \\ ${ }^{10}$ Grupo de Radioterapia Oncológica, Instituto Nacional de Cancerología, Bogotá 9-85, Colombia \\ ${ }^{11}$ Departamento de Oncología, Hospital Santa Rosa, Lima 95405, Peru \\ ${ }^{12}$ Unidad de la Mama, Oncosalud-AUNA, Lima 15036, Peru
}

Correspondence to: Carlos Vallejos. Email: cvallejos@oncosalud.pe

\begin{abstract}
Breast cancer (BC) is a highly prevalent malignancy in Latin American women, most cases being diagnosed at locally advanced or metastatic stages when options for cancer care are limited. Despite its label as a public health problem in the region, Latin American BC patients face several barriers in accessing standard of care treatment when compared with patients from developed countries. In this review, we analyse the landscape of the four main identified barriers in the region: i) high burden of locally advanced/advanced BC; ii) inadequate access to medical resources; iii) deficient access to specialised cancer care and iv) insufficient BC research in Latin America. Unfortunately, these barriers represent the main factors associated with the $\mathrm{BC}$ poor outcomes seen in the region. Targeted actions should be conducted independently by each country and as a region to overcome these limitations and create an enhanced model of BC care.
\end{abstract}

Keywords: breast cancer, Latin America, locally advanced breast cancer, public health

Published: 22/01/2019

Received: 03/07/2018

ecancer 2019, 13:897 https://doi.org/10.3332/ecancer.2019.897

Copyright: (C) the authors; licensee ecancermedicalscience. This is an Open Access article distributed under the terms of the Creative Commons Attribution License (http://creativecommons.org/licenses/by/3.0), which permits unrestricted use, distribution, and reproduction in any medium, provided the original work is properly cited. 


\section{Introduction}

Breast cancer $(B C)$ is a high-burden malignancy in Latin American women with $\approx 200,000$ new cases per year and accounting for more than 52,000 deaths yearly [16]. The high mortality in this region may be explained by reasons such as late stages at diagnosis, lack of access to specialised cancer centres and limited health insurance coverage of high-cost drugs, as previously addressed by others [26].

Unfortunately, BC was not included in the public health agenda in Latin America (LATAM) until 1980. Dramatic changes in the epidemiology of this disease, mainly characterised by the rapid increase in incidence and mortality, have been occurring since 1960 and have led this malignancy to gain interest as a public health issue [49].

LATAM countries have contrasting differences in incidence rates (age-standardised) of BC with the highest incidence in Argentina (73.0 per 100,000), Uruguay (65.2 per 100,000) and Brazil (62.9 per 100,000), while the lowest incidence is recorded in Guatemala (26.2 per 100,000) and Bolivia (26.5 per 100,000) [16]. The mortality rates continue increasing in LATAM, except in Chile, Uruguay and Argentina, where a decreasing trend is observed [16]. The outcomes in this region are also heterogeneous (as seen in the mortality/incidence rate), with remarkable differences in the mortality/incidence ratio compared with developed countries such as the United States or Canada (Figure 1).

Another distinctive feature of BC presentation in LATAM is that young women comprise a large proportion of diagnosed cases. In addition, there is a higher prevalence of triple-negative BC $(\approx 20 \%)$ compared with other regions of the world, which leads to the larger burden of aggressive tumours [66, 70].
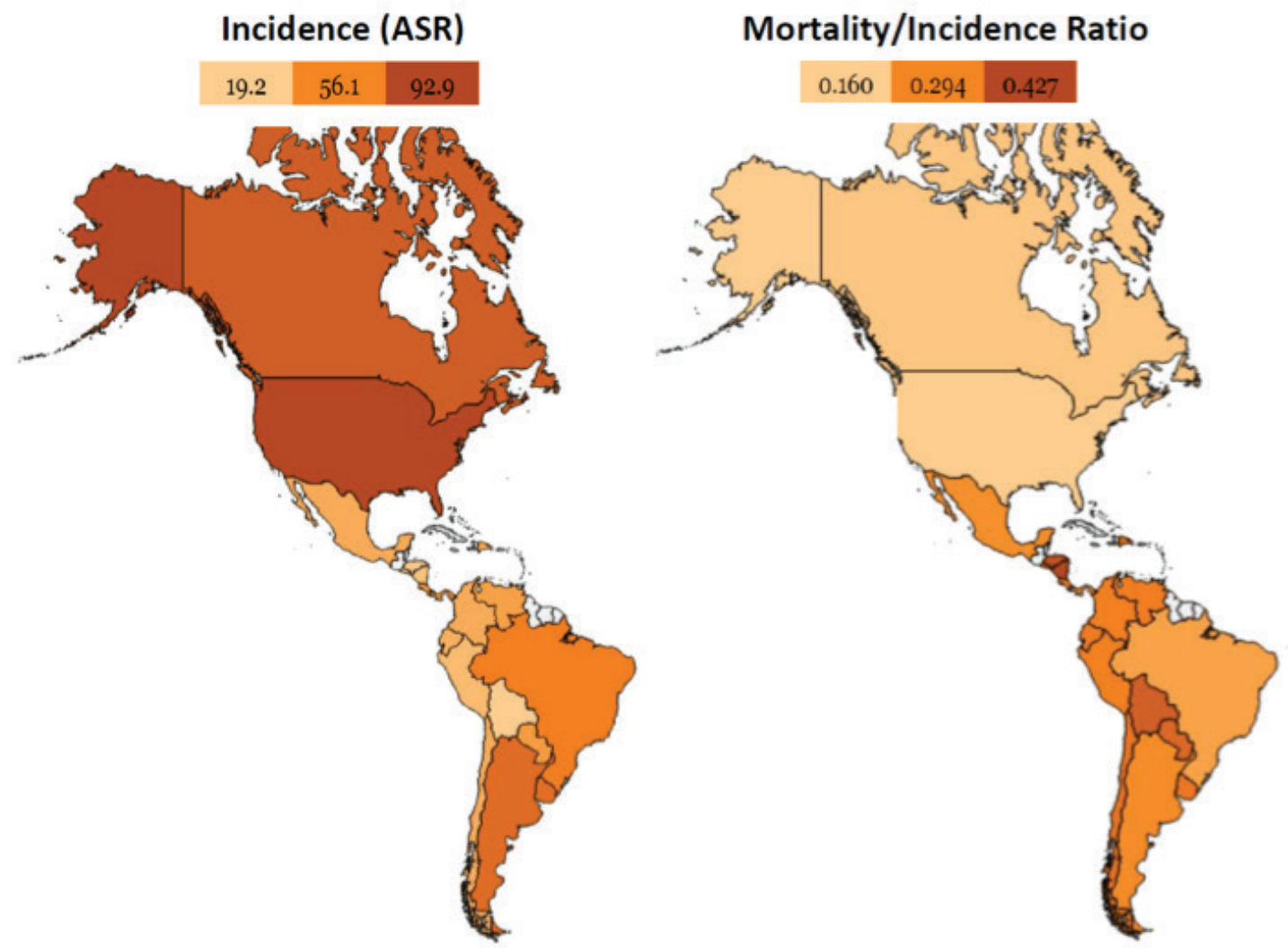

Figure 1. Comparison between the United States and Canada with Latin American countries. Despite a lower incidence of breast cancer in LATAM, the outcomes are worse compared to the United States and Canada. Heat maps designed in www.openheatmap.com and based in GLOBOCAN 2012 data. 
Locally advanced breast cancer (LABC) is a term used to define a wide and heterogeneous group of large-sized tumours, node-positive or inoperable $\mathrm{BC}$ with often unfavourable prognosis. Its management remains challenging and involves a multidisciplinary team of cancer physicians [62]. Although recent advances in systemic treatment have improved the operability rates and the outcome of LABC, these benefits have not necessarily been seen in Latin American patients.

We identified four main barriers for the management of LABC in LATAM: i) high burden of locally advanced/advanced BC, ii) inadequate access to medical facilities and resources, iii) deficient access to specialised management and iv) insufficient BC research in LATAM (box 1). We conducted a literature search in Scopus and PubMed using combinations of the text words 'Breast Cancer' (and synonyms), 'Cancer Care', 'Breast Cancer Screening', 'Treatment Outcome', 'Cancer Care Facilities', 'Barriers', "Latin America"' and 'Research'. Two researchers screened article titles, abstracts and full-texts to identify papers addressing totally or partially any of the identified barriers. Duplicated articles or those with non-relevant content were excluded. An additional search in Google Scholar and citation searching was conducted to find relevant papers. Data on cancer incidence and mortality and time trends were retrieved from the project GLOBOCAN 2018 [16]. Data of clinical research were retrieved from www.clinicaltrials.gov

In order to find out about patterns of care in LABC, We sent a questionnaire to nine oncologists from Chile, Colombia, Bolivia, Brazil, Mexico, Peru and Venezuela and we asked them to distribute the survey between colleagues working in public and private institutions. Surveys were returned by oncologists from Mexico $(n=7)$, Bolivia $(n=4)$, Peru $(n=3)$, Chile $(n=1)$ and Colombia $(n=1)$.

Limitations of our analysis included a biased interpretation of the survey due to the small sample of participants and in addition, because of the limited number of publications from some LATAM countries. Finally, invisible barriers and some public health issues could be underrepresented in this article.

Box 1. Barriers and opportunities to improve in the management of locally advanced breast cancer in LATAM.

\begin{tabular}{|c|c|}
\hline Barriers to the management of LABC & Improvement opportunities \\
\hline \multirow{3}{*}{$\begin{array}{l}\text { i) High burden of locally advanced/advanced breast } \\
\text { cancer }\end{array}$} & Improve the access to breast cancer screening \\
\hline & To train health promoters \\
\hline & $\begin{array}{l}\text { Reducing the time from diagnosis to the special- } \\
\text { ised cancer care }\end{array}$ \\
\hline \multirow[b]{2}{*}{ ii) Inadequate access to medical resources } & Cancer care descentralisation \\
\hline & $\begin{array}{l}\text { Involvement of academia to improve the access } \\
\text { to genetic testing and other molecular tests }\end{array}$ \\
\hline \multirow{4}{*}{ iii) Deficient access to specialised cancer care } & $\begin{array}{l}\text { To elaborate on plans to improve the funding of } \\
\text { cancer care }\end{array}$ \\
\hline & Improve the access to fertility preservation \\
\hline & $\begin{array}{l}\text { To develop strategies to access to high-cost } \\
\text { drugs }\end{array}$ \\
\hline & Improve the access to psychological support \\
\hline \multirow{4}{*}{ iv) Insufficient breast cancer research in LATAM } & Empower local investigators \\
\hline & To develop more clinical research in LABC \\
\hline & Increase the number of publications \\
\hline & $\begin{array}{l}\text { To develop strategies to improve the regulatory } \\
\text { context }\end{array}$ \\
\hline
\end{tabular}




\section{High burden of locally advanced/advanced BC}

Mammography represents the most effective tool for the detection of BC in its earliest and most treatable stages [42]. This method has shown a reduction in BC mortality of up to $23 \%$ in women aged 50 years or older and it is not recommended to young women because mammography sensitivity can be as low as $68 \%$ [6]. Its effectiveness is directly related to a series of technical factors that must be met, as well as accessibility, conditions that are difficult to guarantee in most of LATAM and the Caribbean [42].

In order to establish guidelines to ensure the quality of mammography programmes and their accessibility, in 2016, the Pan American Health Organization/World Health Organization (PAHO/WHO) published the manual 'Quality assurance of mammography services: Basic standards for Latin America and the Caribbean'. This document includes several recommendations such as: screening every 2 years by population-based mammography in women between 50 and 69 years, availability of qualified health personnel (technologists, radiologists, etc.), sufficient financial resources to support the services for the acquisition and maintenance of equipment, development of validated protocols to perform and interpret mammograms and promotion of screening and educational campaigns for the population and health service providers, among others [41].

However, the outlook among the most vulnerable populations in LATAM is the opposite, evidencing low-quality patient care, insufficient health service resources for the delivery of results and very low integration with the rest of the health system. In both Brazil and Mexico, the average time between the first contact with the health service and the beginning of treatment is 7 months [60]. In a study conducted in Colombia, the mean delay was 137 days, where higher socioeconomic status and educational level were associated with shorter time to diagnosis and treatment [45].

In a study conducted in northern Peru, where breast screening with a mammogram is unavailable, the previous exposition to clinical breast exam was associated to diagnosis at earlier stages and less BC treatment delay, defined as > 3 months between the discovery of symptoms by the patient and the beginning of treatment [52]. This indicates a potential benefit of the clinical breast examination in some settings and it is recommended by the Breast Health Global Initiative consensus panel for low-resource and middle-resource countries [3].

In terms of coverage, the WHO estimates that for screening mammography to achieve some impact, it must reach at least $70 \%$ of the target population. For almost every country in LATAM, however, screening mammography coverage does not even approach that figure, not even in countries where it is free. For example, Colombia has a $54 \%$ reach but in Argentina, Chile and Costa Rica, it is between $32 \%$ and $46 \%$, while in Mexico, it is only $22 \%$ [15].

Studies in Brazil, Chile, Colombia and Mexico have reported that less than 22\% of women are diagnosed at clinical stage I of BC [26]. The exception in the region is Uruguay, where mammography was established as a mandatory requirement for women who want to work, with a high population coverage (75\% in 2005$)$, associated with a positive impact, since approximately $40 \%$ of diagnosed cases were in stage I $[5,60]$.

Recent studies suggest that mammography-based screenings programmes tend to over-diagnose small tumours less likely to be aggressive or growth rather than diminish the incidence of tumours $\geq 5 \mathrm{~cm}$ that has strong effect in the BC mortality and also that not offering screening to women at low risk reduces over-diagnosis and improves the cost-effectiveness of BC screening programmes [43, 68]. Although extrapolating these findings for LATAM could be complicated because some sociocultural and biological differences exist with other populations (higher prevalence of triple-negative breast tumours), additional strategies to reduce the burden of locally-advanced and metastatic BC should be evaluated.

In cases where mammography is not available; ultrasound could be an alternative for young patients and patients with dense breasts. Some studies report an improved sensitivity of ultrasound compared to mammogram as the first-line screening in this population [40]. However, ultrasound has little to offer in mass screening because of its inability to detect microcalcifications and a high rate of false positive findings, so cannot replace the mammogram [20].

On the other hand, the involvement of health promoters could be an important strategy to improve BC screening programmes. A study by Coronado et al [19] conducted in Washington State with the aim of assessing the efficacy of a clinic and patient-level programme to increase BC screening, recruited 516 Latinas (42-74 years old) that were randomised to a control arm (usual care) or a promotora-led, motivational interviewing intervention. One-year rates of mammograms were $19.6 \%$ versus $11.0 \%$ for the control versus intervention arm, respectively [9]. 
Latin American countries present a higher incidence of locally advanced tumours and late stages at diagnosis compared with developed countries. In our survey involving oncologists from Bolivia, Chile, Colombia, Mexico and Peru, rates of LABC were variable in different scenarios with frequencies up to $70 \%$ of all BC cases. Higher incidences were reported in some settings in Bolivia, Chile and Mexico (Table 1). Previously published data for the region described LABC frequencies ranging between $15 \%$ and $30 \%$ [26]. Education and health promotion is a major issue in the region and the availability of facilities for cancer screening does not imply a vast use of these services [2].

In Peru, the 'Plan Esperanza' has had a great impact on funding for cancer care in patients with low socio-economic status. Free access to cancer care has been offered to $\approx 70 \%$ of patients attending the National Cancer Institute of Peru; however, despite investing resources in treatment, the burden of LABC has not decreased significantly (57.8\% versus $53.2 \%$ for the periods $2010-2012$ and $2012-2015)$. This shows that additional efforts should be made for early diagnosis $[24,65]$.

\section{Inadequate access to medical resources}

In low resource settings, centralisation of cancer care facilities is a frequent barrier to achieving the standard of care seen in developed countries. Although there is current advocacy to centralise procedures to centres treating a high volume of patients because better outcomes are obtained compared with centres attending fewer patients; in developing countries, this policy would contribute greatly to inequalities [58]. Geography is an important barrier to receiving treatment and patients living far away from cancer care facilities are less likely to receive treatments such as chemotherapy and radiotherapy, regardless of their insurance status [29,30]. Oncologists, aware of these limitations, are dissatisfied with the insufficient access to appropriate medical care that patients experience [8].

Disparities in the access to specialised facilities are a feature of LATAM, where few specialised oncologic centres exist and are mainly located in a minority of high-income regions [46].

Additionally, logistic barriers in existing institutions further limit the availability of quality cancer screening and care services. For example, in Colombia, institutions that provide cancer care offer a limited number of specialised services, which leads to delays in a multidisciplinary setting [12]. In Peru, despite the existence of three specialised cancer centres and multiple oncological units in general hospitals, health services are saturated, which impact negatively on the distribution of clinical stages at diagnosis of several cancers, including BC [64].

Regarding radiotherapy services, frequently used as an indicator of cancer-control, infrastructure availability, only Chile and Brazil have enough facilities and machine units to cover their demand. In contrast, Bolivia, Paraguay and Peru have the greatest unmet demand [60]. Furthermore, an audit from the International Atomic Energy Agency performed at several centres in LATAM showed deficiencies in the quality of services such as processes, organisational aspects, education/training and number of radiation oncologists, medical physicists and medical technologists [53].

Despite the wide access to the basic panel of immunohistochemistry (Oestrogen receptor, progesterone receptor and HER2) in the region, the access to Fluorescence In Situ Hybridization (FISH) or Chromogenic In Situ Hybridization (CISH) to assess HER2 is limited. On the other hand, there is scarce information about the technical quality of immunohistochemistry and FISH testing in the region [21].

Clinical genetics and genetic research had early development in LATAM since the 1960s in countries like Brazil, Mexico and Argentina, while some countries, including Argentina, Brazil, Colombia and Mexico have current national guidelines recommending genetic counselling and testing [8,44]. BRCA1/2 mutation testing, as well as other genetic testing of cancer predisposition genes, is offered by local or transnational laboratories; however, the costs are prohibitively expensive for patients in the public health system in LATAM and are not covered by public healthcare insurances. This economic barrier led to the development of the HISPANEL, a 114 recurrent Hispanic BRCA mutations panel at low cost. These 114 mutations were selected from US Hispanic patients and validated in Mexican patients. Unfortunately, the HISPANEL has limitations (68\% of sensitivity) and negative cases should be assessed with traditional tests [8].

Genomic tests such as MammaPrint, Oncotype DX, Endopredict and PAM50 are offered in the region by sales representatives from foreign companies. Peru participated in the prospective validation of Oncotype DX [56]. Oncotype DX is covered by public or private insurances in Argentina, Colombia, Brazil, Peru and Mexico, while in Chile and Bolivia it corresponds to an out of pocket cost. Although the benefit of low-risk patients in avoiding adjuvant chemotherapy is clear, there is a lack of pharmacoeconomic studies in each LATAM country. 
Table 1. Features of management of $L A B C$ in selected countries of Latin America

\begin{tabular}{|c|c|c|c|c|c|c|c|c|c|c|c|}
\hline \multirow{3}{*}{ QUESTIONS } & \multicolumn{2}{|c|}{ BOLIVIA } & CHILE & COLOMBIA & \multicolumn{2}{|c|}{ MEXICO } & MEXICO & \multicolumn{2}{|c|}{ PERU } & \multicolumn{2}{|c|}{ PERU } \\
\hline & \multicolumn{2}{|c|}{$(n=4)$} & $(n=1)$ & $(n=1)$ & \multicolumn{2}{|c|}{$(n=7)$} & $(n=1)$ & \multicolumn{2}{|c|}{$(n=3)$} & \multicolumn{2}{|c|}{$(n=2)$} \\
\hline & MEDIAN & RANGE & & & MEDIAN & RANGE & & MEDIAN & RANGE & MEDIAN & RANGE \\
\hline SETTING & \multicolumn{2}{|c|}{ Public } & Private & Public & \multicolumn{2}{|c|}{ Public } & Private & \multicolumn{2}{|c|}{ Public } & \multicolumn{2}{|c|}{ Private } \\
\hline $\begin{array}{l}\% \text { of patients with } \\
\text { bone scan for analysis } \\
\text { of bone metastases at } \\
\text { diagnosis }\end{array}$ & 62.5 & $20-95$ & 100 & 100 & 67.5 & $0-100$ & 0 & 50 & $50-60$ & 55 & $10-100$ \\
\hline $\begin{array}{l}\% \text { of Hereditary/famil- } \\
\text { iar cancer patients } \\
\text { attending genetic } \\
\text { counseling }\end{array}$ & 5 & $0-35$ & 20 & 45 & 67.5 & $0-100$ & 90 & 10 & $5-30$ & 15 & $10-20$ \\
\hline $\begin{array}{l}\% \text { of breast cancer } \\
\text { patients lacking a } \\
\text { private or public } \\
\text { insurance }\end{array}$ & 25 & $25-75$ & 0 & 5 & 15 & $0-90$ & 0 & 25 & $20-60$ & 37.5 & $25-50$ \\
\hline $\begin{array}{l}\% \text { of } L A B C \text { cases at } \\
\text { diagnosis }\end{array}$ & 70 & $30-85$ & 70 & 50 & 60 & $15-70$ & 30 & 40 & $30-40$ & 25 & $20-30$ \\
\hline $\begin{array}{l}\% \text { of LABC patients } \\
\text { accessing to neoadju- } \\
\text { vant therapy }\end{array}$ & 72.5 & $10-90$ & 60 & 95 & 92.5 & $60-100$ & 100 & 70 & $70-90$ & 95 & $90-100$ \\
\hline $\begin{array}{l}\% \text { of } L A B C \text { patients } \\
\text { accessing to clinical } \\
\text { trials }\end{array}$ & 0 & 0 & 0 & 35 & 2.5 & $0-10$ & 10 & 0 & $0-10$ & 17.5 & $5-30$ \\
\hline $\begin{array}{l}\% \text { of } L A B C \text { patients } \\
\text { managed with } \\
\text { strategies of fertility } \\
\text { preservation }\end{array}$ & 5 & $0-15$ & 20 & 20 & 2.5 & $0-10$ & 15 & 0 & $0-30$ & 12.5 & $5-20$ \\
\hline $\begin{array}{l}\% \text { of HER2 LABC } \\
\text { patients with access to } \\
\text { trastuzumab treatment }\end{array}$ & 35 & $20-50$ & 100 & 95 & 100 & $90-100$ & 100 & 50 & $0-90$ & 70 & $70-70$ \\
\hline $\begin{array}{l}\% \text { of LABC with } \\
\text { access to oncoplastic } \\
\text { breast surgery }\end{array}$ & 10 & $10-50$ & 90 & 80 & 70 & $10-100$ & 80 & 70 & $15-80$ & 60 & $50-70$ \\
\hline $\begin{array}{l}\% \text { of LABC patients } \\
\text { with axillary complete } \\
\text { response after neoad- } \\
\text { juvant chemotherapy } \\
\text { undergoing sentinel } \\
\text { node biopsy }\end{array}$ & 20 & $0-45$ & 40 & 35 & 25 & $0-95$ & 30 & 15 & $0-15$ & 32.5 & $15-50$ \\
\hline $\begin{array}{l}\% \text { of LABC patients } \\
\text { initiating adjuvant } \\
\text { chemotherapy after } 8 \\
\text { weeks }\end{array}$ & 52.5 & $10-95$ & 20 & 25 & 12.5 & $0-95$ & 0 & 40 & $30-90$ & 20 & $20-20$ \\
\hline $\begin{array}{l}\% \text { of LABC with Boost } \\
\text { with Brachytherapy } \\
\text { or intraoperative } \\
\text { Radiotherapy with } \\
\text { electrons or fotons }\end{array}$ & 0 & 0 & 25 & 20 & 0 & $0-10$ & 0 & 0 & $0-40$ & 12.5 & $10-15$ \\
\hline
\end{tabular}


In LATAM, as well as in other developing countries, cancer genomics resources and specialised personnel are scarce-tools that would be useful for cancer prevention, early diagnosis, personalised treatments, genetic counselling and research [8, 59]. Currently, 221 NextGeneration Sequencing (NGS) platforms have been reported to exist in LATAM, which are distributed both in public and private institutions. Brazil and Mexico have the highest numbers of these platforms, while Peru and Ecuador have the lowest. Furthermore, Mexico, Brazil, Argentina, Colombia and Chile are the leading countries in terms of installed facilities, cancer genetic research groups, educational programmes in genomics and medium-impact publications in the field [61].

\section{Deficient access to specialised cancer care}

LATAM countries have made important progress in improving their health systems. However, much more need to be done to ensure sufficient access to health care resources for the majority of the population [10]. Issues regarding access to specialised BC management specific to the LABC setting in LATAM are listed in Table 1.

One of the most important issues is the financial coverage of cancer care and the dramatic contrast that exists between public and private healthcare services (Table 1). Several efforts are being conducted in LATAM to improve funding for cancer care in poor patients. In Peru, data from Instituto Nacional de Enfermedades Neoplásicas (INEN) showed that there was a rise in attention rates of patients covered by social funds from the National Cancer Control Programme (Plan Esperanza), from $47.5 \%$ in 2011 to $\approx 70 \%$ in 2017 [24]. We expect that the improved access to treatment through the 'Plan Esperanza' will translate into positive outcomes in the following years.

The data from the survey carried out in a group of selected LATAM countries demonstrate concerning information about the proportion of LABC patients lacking neoadjuvant chemotherapy, where a high disparity between settings is observed (Table 1). In addition, this survey shows that a small proportion of patients with axillary complete clinical/imaging response after neoadjuvant chemotherapy have further sentinel node biopsy, indicating trends for more aggressive surgeries (Table 1). In the Peruvian experience, it is easier to evaluate the sentinel node at the surgery than before the neoadjuvant treatment due to long waiting periods for appointments for biopsy procedures.

Delays in treatment commonly occur within the region. The time between the completion of neoadjuvant chemotherapy and surgery is more than 8 weeks in $54 \%$ of Peruvian patients in public institutions [47]. In our survey, a diverse proportion of LABC patients initiating adjuvant chemotherapy after 8 weeks were observed in different settings (Table 1). Such lags in treatment are especially relevant, as a delay of $\geq 61$ days after surgery confers worse survival in triple negative and HER2 subtypes, compared with initiation of treatment within the first 30 days following surgery [17].

Regarding radiotherapy, there is low access to brachytherapy or intraoperative radiotherapy for patients with LABC, which reflects a low investment in radiotherapy machines.

Barriers to access to high-cost cancer medications have been previously addressed in the region [21]. In our survey, patients with HER2 positive LABC had different levels of access to trastuzumab, a humanised monoclonal antibody used for the management of HER2 positive disease, and that is included in the list of essential medications by the WHO [69]. The lowest levels of access were reported for Bolivia.

Potential solutions to overcome existing barriers for access to high-cost drugs in LATAM, as proposed by Ruiz et al [54], include: i) increase and redistribution of budget for cancer care; ii) strengthening cost-effectiveness analyses and health technology assessment; iii) collective negotiation and procurement; iv) creation of resource funds; v) differential pricing policies; vi) use of generics and biosimilars through flexibility of patent laws; vii) evidence-based adaptation of treatment schemes and vii) participation in clinical research [54].

Access to oncoplastic breast surgery is variable. The experience in Peruvian public hospitals shows it is easier to offer this procedure in hospitals with a low volume of patients, as this surgical procedure involves additional time (up to 1.5 hours to perform a contralateral breast symmetrisation).

Regarding fertility preservation procedures, strategies are almost nonexistent in the region (Table 1). Moreover, it is not an issue frequently discussed with patients [67]. Fertility preservation has great importance in our region because LATAM has a higher prevalence of BC in young women compared with other regions [66]. A study conducted to evaluate the acceptance of chemotherapy in the context of infertility 
risk in patients aged $\leq 35$ years found that South American women require a greater chance of cure $(>20 \%)$ in order to accept chemotherapy in the adjuvant setting, in contrast to women from other regions [55]. Strategies for fertility preservation suitable for Latin American women include the use of gonadotropin-releasing hormone agonists and embryo/oocyte or ovarian tissue cryopreservation. The main barrier is the economic cost, as this is frequently an out of pocket expense, and a lack of specialised centres [27].

Likewise, all people with BC should receive specialised psychological support, and when it is also necessary, psychiatric support; since it has been reported that between $22 \%$ and $47 \%$ of patients diagnosed with BC may suffer from anxiety and depression and approximately $33 \%$ report sexual problems. Although psychological care has improved and has become more widespread in recent years, there is still a lack of specialised professionals in this area, as well as standardisation in its evaluation and treatment [36].

There is an insufficient investigation into psycho-oncology leading to the failure to address barriers to it adequately and difficulties in putting together strategies to improve the quality of life of patients while research in this area is mainly conducted in patients from developed countries. The diagnosis of BC causes in patients carries an important psychological impact that should be evaluated to provide adequate psychological support [11]. Levels of distress in cancer patients are higher at the beginning of chemotherapy [13]. In addition, health services should give attention not only to patients but also to members of their family [50].

In Brazil, psychological counselling was implemented in public and private institutions as part of the criteria for the registry of oncological centres (Ministry of Health's 1998 Protocol 3535/GM). With programmes multiplied across the country, Brazilian psycho-oncology has contributed to the integration of psychosocial care at different stages of cancer care for patients and their families [13]. In Mexico, improving the quality of life and psychological rehabilitation of cancer patients are included in the objectives of the National Comprehensive Cancer Control Programme [48].

Finally, excessive bureaucracy and corruption in the public health system in Latin American countries need to be addressed and confronted. These issues are a barrier to modernisation of the health sector and delivering high-quality care.

\section{Insufficient breast cancer research}

In LATAM, several barriers for conducting clinical research exist. In a survey of Latin-American, American Society of Clinical Oncology (ASCO) members, regulatory, low budgets, high costs and poor financial management were identified as barriers to conducting successful clinical research [18]. An analysis of the time to approval of the Adjuvant Lapatinib And/Or Trastuzumab Treatment Optimisation trial conducted in 44 countries showed the longest time in South America (average, 236 days), followed by Africa (130 days), Asian-Pacific (62 days), Europe (52 days) and North America (26 days) [35]. In a recent analysis, other identified barriers included lack of economic investment, lack of national cancer registries and the negative attitude of government authorities towards clinical research [51].

On the other hand, strengths can also be identified, such as the high educational level of researchers and staff, the common interests of patients and researchers, as well as the desire to participate in large academic trials [18]. In addition, there are several local and regional cooperative groups empowering clinical research activities and Latin American investigators [1].

A search of interventional trials in $L A B C$ registered on clinicaltrials.gov showed few studies registered in South American countries. Brazil had the highest number of registered studies $(n=40)$, followed by Argentina $(n=25)$ and Peru $(n=18)$ (Figure 2). This pattern is also observed in clinical trials of diseases other than BC, where there are few trials in LATAM in comparison with North America or Europe. This gap is also translated to publications and evidenced by carrying out an analysis of the abstracts presented at the meetings of ASCO, ESMO, ASTRO and ASH. ESMO, ASTRO and ASH, where Brazil has the highest scientific production [1].

Despite their willingness to participate, the proportion of patients accessing clinical trials in the LABC setting is very low or absent in most Latin American countries (Table 1).

Despite the wide availability of the GLOBOCAN data to retrieve epidemiological information on cancer, Latin American countries need more and better cancer registries in order to obtain more robust data, as previously described [63]. 


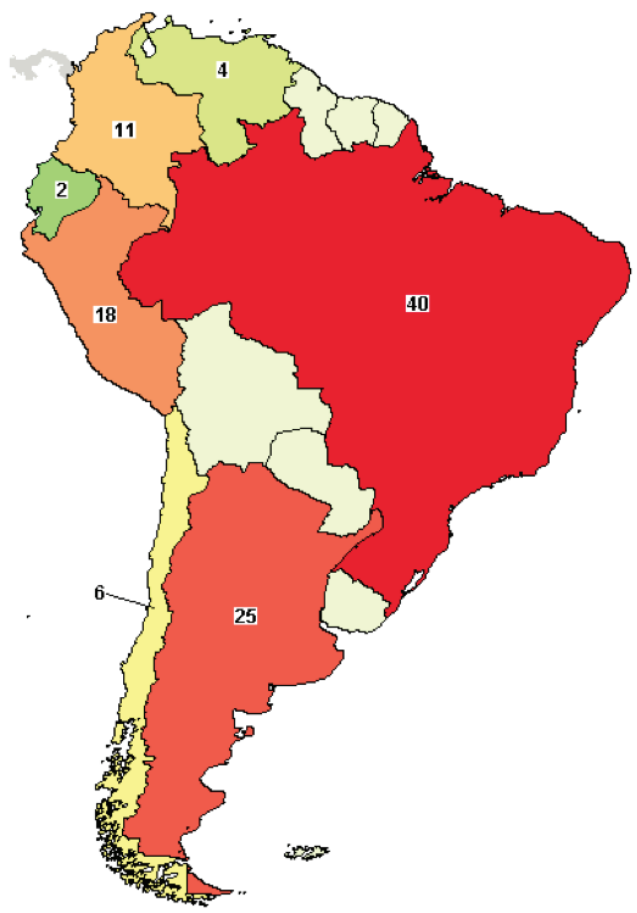

Figure 2. Interventional clinical trials in LATAM: Brazil, Mexico (28 trials, not shown in the map) and Argentina had greater participation in clinical trials in LABC. Source: clinicaltrials.gov. Search criteria: breast cancer, interventional studies, phase I-III trials and refined by the term 'locally advanced' Accessed on April 26th, 2018.

\section{Others barriers for the management of LABC}

Despite advances in diagnosis and treatment of BC, factors such as ethnicity, environment, culture, education, socioeconomic and lifestyle are barriers that hinder its early detection, which in turn causes differences in the incidence and prognosis of people who even live in the same geographical area $[23,32,33]$.

Social and cultural barriers impede the access of patients to programmes for the early detection and treatment of BC. Some of them are related to fears, such as suffering, dying, abandoning their children, ceasing to be an object of desire, losing their husbands; taboos about the incurability of cancer, perceiving it as synonymous with death; and the generation of diverse feelings such as anguish, pain, impotence, anger, compassion and extreme concern [37]. It has been reported that although the group of women belonging to the low socioeconomiccultural group has a low incidence of BC, they have a worse prognosis since their participation in screening programmes is lower, and at the time of diagnosis, the patients present tumours of a large diameter and a higher incidence of locally advanced and metastatic disease [14].

Regarding the level of education, several studies have shown that women with a low level of education are more likely to experience longer delays both in getting a correct diagnosis and beginning their treatment $[25,57]$. This can be explained by the fact that people with a low level of education do not have enough information or have incorrect information for understanding the importance of prevention and early detection of diseases like cancer, to which is added poor access to healthcare services [34, 38, 39]. For example, in a study conducted in Brazil, it was reported that the average time for the final diagnosis of BC was $102.5 \pm 165.5$ days, where most of the cases had a delay of $72.3 \pm 54.0$ days to start their treatment, especially in women with a low level of education. In contrast, in the non-delayed cases, treatment was initiated in $19.6 \pm 8.8$ days [31]. 


\section{Is it possible to improve the outcomes of LABC in LATAM?}

A decrease in cancer mortality trends through time has been observed worldwide. However, although a decrease in the mortality of BC is observed, it remains stable in several LATAM countries [7, 22]. As an example, Gonzaga et al [19] showed different spatiotemporal trends of mortality in Brazil. Globally, the mortality rates are stable; however, a decrease in mortality is seen in more developed states [19].

Better outcomes are seen in BC patients who have private insurance in contrast to those who have public insurance [28]. This reflects the disparities in the access to healthcare facilities. The 5-years overall survival for BC with the regional disease is $47.4 \%$ for countries with less developed health services contrasting to $75.4 \%$ for countries with more developed health services [3]. These data show that access to funding for cancer care is important, however, the implementation of state-of-art facilities is also essential. The improvement of radiotherapy facilities is urgently needed and local guidelines considering available resources should be established.

There are few available regional scientific articles showing the outcomes of LABC patients. For Mexico, the 5-years OS is over 85\% [4], representing an improvement in the outcomes previously published for this country (29.4\%-34.8\%) [26]. This improvement is also seen in Brazil, where the cause-specific survival for stage III is $58 \%$ compared to past periods where OS rates to 5 -years reported were between $15.1 \%$ and $34.3 \%$.

On the other hand, there is scarce information in several LATAM countries. Additional support should be conducted in these countries in order to develop, improve and empower local research groups.

It is possible to improve the outcomes of LABC in LATAM, as we can see in the results obtained by patients that have private insurance and are treated by a multidisciplinary group of specialists, but there is much organisational work to be done to allow greater populations to access the same quality of treatment.

Several strategies have been proposed to improve the results of LABC and other types of BC in low and middle-income countries; such as: 1) invest financially in awareness campaigns and training of community health workers in order to educate the population and at the same time perform clinical breast exams, 2) increase the specialised mastectomy training in order to improve the quality and obtain better results in patients; 3 ) implement cost-effective chemotherapeutic regimens to increase the likelihood that patients will receive optimal care, improving cancer outcomes; 4) establish adequate infrastructures to perform radiation therapies and training specialised personnel and 5) implementing cheaper strategies in radiation therapy; for example, shortening the regimens of therapies while maintaining the effectiveness of the treatment [6].

\section{Conclusions}

There are several barriers to the management of LABC in LATAM that are not being adequately addressed and are responsible for the poor outcomes seen in the region. To overcome these barriers, a set of activities should be carried out, including the improvement of BC screening programmes (more funding is urgently needed), increasing the funding of cancer care, adopting or adapting national clinical guidelines and developing more research. Improving the outcomes and the quality of life of patients will be possible if these efforts are conducted adequately.

\section{Conflicts of interest statement}

The authors declare they have no conflicts of interest for this manuscript. 


\section{References}

1. Acevedo AM, Gómez A, and Becerra HA, et al (2014) Distribution and trends of hematology and oncology research in Latin America: a decade of uncertainty Cancer 120(8) 1237-1245 https://doi.org/10.1002/cncr.28539 PMID: 24382827

2. Alarcon-Rozas A, Villakres K, and Cardenas R (2005) Perceptions of breast and cervix cancer prevention in two populations of women in Peru: impact of knowledge and access to health service J Clin Oncol 23(S16) 6120-6120 https://doi.org/10.1200/ jco.2005.23.16 suppl.6120

3. Anderson BO, Cazap E, and El Saghir NS, et al (2011) Optimisation of breast cancer management in low-resource and middleresource countries: executive summary of the Breast Health Global Initiative consensus, 2010 The Lancet Oncology 12(4) 387-398 [https://doi.org/10.1016/S1470-2045(11)70031-6] PMID: 21463833

4. Arce-Salinas C, Aguilar-Ponce JL, and Villarreal-Garza C, et al (2014) Overweight and obesity as poor prognostic factors in locally advanced breast cancer patients Breast Cancer Res Treat 146(1) 183-188 https://doi.org/10.1007/s10549-014-2977-8

5. Arie S (2013) Uruguay's mandatory breast cancer screening for working women aged 40-59 is challenged BMJ Clinical Research Ed 346 f1907

6. Balogun OD and Formenti SC (2015) Locally advanced breast cancer-strategies for developing nations Frontiers in Oncol $\mathbf{5}$ [https://doi.org/10.3389/fonc.2015.00089]

7. Bray F and Piñeros M (2016) Cancer patterns, trends and projections in Latin America and the Caribbean: a global context Salud Publica De Mexico 58(2) 104-117 https://doi.org/10.21149/spm.v58i2.7779 PMID: 27557369

8. Chavarri-Guerra Y, Blazer KR, and Weitzel JN (2017) Genetic cancer risk assessment for breast cancer in Latin America Revista De Investigacion Clinica; Organo Del Hospital De Enfermedades De La Nutricion 69(2) 94-102

9. Coronado GD, Beresford SA, and McLerran D, et al (2016) Multilevel intervention raises latina participation in mammography screening: findings from ¡fortaleza latina! cancer Epidemiol Biomarkers Prev 25(4) 584-592 https://doi.org/10.1158/1055-9965. EPI-15-1246

10. Cotlear D, Gómez-Dantés O, and Knaul F, et al (2015) Overcoming social segregation in health care in Latin America The Lancet 385(9974) 1248-1259 [https://doi.org/10.1016/S0140-6736(14)61647-0]

11. de Menezes NNT, Schulz VL, and Peres RS (2012) Breast cancer diagnosis' psychological impact: a study since patients' reports in a support group Estud Psicol 17(2) 233-240

12. de Vries E, Buitrago G, and Quitian H, et al (2018) Access to cancer care in Colombia, a middle-income country with universal health coverage Journal of Cancer Policy 15 104-112 [https://doi.org/10.1016/i.jcpo.2018.01.003]

13. Decat CS, De Araujo TCCF, and Stiles J (2011) Distress levels in patients undergoing chemotherapy in Brazil Psycho-Oncology 20(10) 1130-1133 https://doi.org/10.1002/pon.1833

14. DeSantis C, Jemal A, and Ward E (2010) Disparities in breast cancer prognostic factors by race, insurance status, and education Cancer Causes and Control: CCC 21(9) 1445-1450 [https://doi.org/10.1007/s10552-010-9572-z]

15. Di Sibio A, Abriata G, and Forman D, et al (2016) Female breast cancer in Central and South America Cancer Epidemiol 44(1) S110-S120 [https://doi.org/10.1016/j.canep.2016.08.010]

16. Ferlay J, Ervik M, and Lam F, et al (2018) Global cancer observatory: cancer today (Lyon, France: International Agency for Research on Cancer) [https://gco.iarc.fr/today] accessed date: 1/11/18 
17. Gagliato D, Gonzalez-Angulo AM, and Lei X, et al (2014) Clinical impact of delaying initiation of adjuvant chemotherapy in patients with breast cancer J Clin Oncol: Official J Americ Soc Clin Oncol 32(8) 735-744 [https://doi.org/10.1200/JC0.2013.49.7693]

18. Gomez H, Pinto J, and Castañeda C, et al (2015) Current barriers for developing clinical research in Latin America: A crosssectional survey of medical oncologists Clin Res Trials 1(2) 22-28 https://doi.org/10.15761/CRT.1000108

19. Gonzaga CMR, Freitas-Junior R, and Curado MP, et al (2015) Temporal trends in female breast cancer mortality in Brazil and correlations with social inequalities: ecological time-series study BMC Public Health 1596 [https://doi.org/10.1186/s12889-0151445-7] https://doi.org/10.1186/s12889-015-1445-7 PMID: 25886146 PMCID: 4331144

20. Gordon PB (2002) Ultrasound for breast cancer screening and staging Radiol Clin North Am 40(3) 431-441 https://doi.org/10.1016/ S0033-8389(01)00014-8

21. Goss PE, Lee BL, and Badovinac-Crnjevic T, et al (2013) Planning cancer control in Latin America and the Caribbean The Lancet Oncology 14(5) 391-436 [https://doi.org/10.1016/S1470-2045(13)70048-2]

22. Hashim D, Boffetta P, and La Vecchia, et al (2016) The global decrease in cancer mortality: trends and disparities Ann Oncol: Offic J Europ Soc Med Oncol 27(5) 926-933 [https://doi.org/10.1093/annonc/mdw027]

23. Hershman D, McBride R, and Jacobson JS, et al (2005) Racial disparities in treatment and survival among women with earlystage breast cancer J Clin Oncol: Offic J Amer Soc Clin Oncol 23(27) 6639-6646 https://doi.org/10.1200/JC0.2005.12.633

24. Instituto Nacional de Enfermedades Neoplásicas (2017) Plan estratégico institucional 2017-2021 modificado

25. Jassem J, Ozmen V, and Bacanu F, et al (2014) Delays in diagnosis and treatment of breast cancer: a multinational analysis Europ J Pub Health 24(5) 761-767 [https://doi.org/10.1093/eurpub/ckt131]

26. Justo N, Wilking N, and Jönsson B, et al (2013) A review of breast cancer care and outcomes in Latin America The Oncologist 18(3) 248-256 [https://doi.org/10.1634/theoncologist.2012-0373] PMID: 23442305 PMCID: 3607519

27. Lambertini M, Goldrat O, and Barragan-Carrillo R, et al (2017) Viable options for fertility preservation in breast cancer patients: a focus on Latin America Revista De Investigacion Clinica; Organo Del Hospital De Enfermedades De La Nutricion 69(2) 103-113

28. Liedke PER, Finkelstein DM, and Szymonifka J (2014) Outcomes of breast cancer in Brazil related to health care coverage: a retrospective cohort study Cancer Epidemiology, Biomarkers and Prevention: A Publication of the American Association for Cancer Research, Cosponsored by the American Society of Preventive Oncology 23(1) 126-133 https://doi.org/10.1158/1055-9965.EPI-13$\underline{0693}$

29. Lin CC, Bruinooge SS, and Kirkwood MK, et al (2016) Association between geographic access to cancer care and receipt of radiation therapy for rectal cancer International Journal of Radiation Oncology, Biology, Physics 94(4) 719-728 [https://doi. org/10.1016/j.jijrobp.2015.12.012] https://doi.org/10.1016/j.jijobp.2015.12.012

30. Lin CC, Bruinooge SS, and Kirkwood MK, et al (2015) Association between geographic access to cancer care, insurance, and receipt of chemotherapy: geographic distribution of oncologists and travel distance Journal of Clinical Oncology: Official Journal of the American Society of Clinical Oncology 33(28) 3177-3185 [https://doi.org/10.1200/JCO.2015.61.1558]

31. Lopes TCR, Gravena AAF, and Demitto M, et al (2017) Delay in diagnosis and treatment of breast cancer among women attending a reference service in Brazil Asian Pacific Journal of Cancer Prevention : APJCP 18(11) 3017-3023 [https://doi.org/10.22034/ APJCP.2017.18.11.3017]

32. Ma BB, Hui EP, and Mok TS (2010) Population-based differences in treatment outcome following anticancer drug therapies The Lancet Oncol 11(1) 75-84 [https://doi.org/10.1016/S1470-2045(09)70160-3]

33. McKenzie $F$ and Jeffreys M (2009) Do lifestyle or social factors explain ethnic/racial inequalities in breast cancer survival? Epidemiologic Reviews 31 52-66 [https://doi.org/10.1093/epirev/mxp007]

34. Melo W, Souza L, and Zurita R, et al (2013) Associated factors in mortality due to breast cancer in northwest Paraná, 2087-2094 
35. Metzger-Filho O, de Azambuja E, and Bradbury I, et al (2013) Analysis of regional timelines to set up a global phase III clinical trial in breast cancer: the adjuvant lapatinib and/or trastuzumab treatment optimization experience The Oncologist 18(2) 134-140 https://doi.org/10.1634/theoncologist.2012-0342

36. National Collaborating Centre for Cancer (UK) (2009) Early and locally advanced breast cancer: diagnosis and treatment (Cardiff, UK: National Collaborating Centre for Cancer) [http://www.ncbi.nlm.nih.gov/books/NBK519155/]

37. Nigenda G, Caballero M, and González-Robledo LM (2009) Barreras de acceso al diagnóstico temprano del cáncer de mama en el Distrito Federal y en Oaxaca Salud Pública de México 51 s254-s262 https://doi.org/10.1590/S0036-36342009000800016

38. Novaes H, Braga P, and Schout D (2006) Factors associated with conducting preventive examinations for cancer in Brazilian women: PNAD 2003 ciência and saúde coletiva 11 1023-1035 https://doi.org/10.1590/S1413-81232006000400023

39. Oliveira E, Pinheiro R, and Melo E, et al (2011) Socioeconomic and geographic conditions of access to mammography in Brazil, 2003-2008 ciência and saúde coletiva 16 3649-3664 https://doi.org/10.1590/S1413-81232011001000002

40. Omidiji OA, Campbell PC, and Irurhe NK, et al (2017) Breast cancer screening in a resource poor country: Ultrasound versus mammography Ghana Med J 51(1) 6-12 https://doi.org/10.4314/gmj.v51i1.2

41. Organización Panamericana de la Salud (2016) Garantía de calidad de los servicios de mamografía: Normas básicas para América Latina y el Caribe (Washington, DC: OPS) [http://iris.paho.org/xmlui/handle/123456789/31293]

42. Pan American Health Organization (2001) Investment in health: social and economic returns (Pan American Health Organization) [http://www.who.int/iris/handle/10665/167766]

43. Pashayan N, Morris S, and Gilbert FJ, et al (2018) Cost-effectiveness and benefit-to-harm ratio of risk-stratified screening for breast cancer: a life-table model JAMA Oncol 4(11) 1504-1510 https://doi.org/10.1001/jamaoncol.2018.1901 PMID: 29978189 PMCID: $\underline{6230256}$

44. Penchaszadeh VB, Beiguelman B (1998) Medical genetic services in Latin America: report of a meeting of experts Rev Panam Salud Publica 3(6) 409-420 https://doi.org/10.1590/S1020-49891998000600013 PMID: 9734220

45. Piñeros M, Sánchez R, and Perry F, et al (2011) Delay for diagnosis and treatment of breast cancer in Bogotá, Colombia Salud Publica De Mexico 53(6) 478-485

46. Pinillos L, Pinto JA, and Sarria G (2017) History of the development of radiotherapy in Latin America Ecancermedicalscience 11 [https://doi.org/10.3332/ecancer.2017.784] PMID: 29225691 PMCID: $\underline{5718250}$

47. Rebaza P, Galarreta J, and Cotrina J, et al (2017) Impacto del intervalo de tiempo entre neoadyuvancia y cirugia en pacientes con cáncer de mama Carcinos 7(1) 12-19

48. Reynoso-Noverón N, Meneses-García A, and Erazo-Valle A, et al (2016) Challenges in the development and implementation of the National Comprehensive Cancer Control Program in Mexico Salud Publica Mex 58(2) 325-333 https://doi.org/10.21149/spm. v58i2.7804

49. Robles SC and Galanis E (2002) Breast cancer in Latin America and the Caribbean. Revista Panamericana De Salud Publica Pan American Journal of Public Health 11(3) 178-185 https://doi.org/10.1590/S1020-49892002000300007

50. Rodríguez-Loyola Y and Costas-Muñíz R (2013) El diagnóstico de cáncer de mamas desde una perspectiva familiar: Retos para la Psico-oncología en América Latina $R$ Interam Psicol 47(1) 121-130

51. Rolfo C, Caglevic C, and Bretel D, et al (2016) Cancer clinical research in Latin America: current situation and opportunities. Expert opinion from the first ESMO workshop on clinical trials, Lima, 2015 ESMO Open 1(4) e000055 [https://doi.org/10.1136/ esmoopen-2016-000055] PMID: 27843620 PMCID: $\underline{5070258}$

52. Romanoff A, Constant TH, and Johnson KM, et al (2017) Association of Previous Clinical Breast Examination With Reduced Delays and Earlier-Stage Breast Cancer Diagnosis Among Women in Peru JAMA Oncology 3(11) 1563-1567 [https://doi. org/10.1001/jamaoncol.2017.1023] 
53. Rosenblatt E, Zubizarreta E, and Izewska J, et al (2015) Quality audits of radiotherapy centres in Latin America: a pilot experience of the International Atomic Energy Agency Radiation Oncology 10(1) 169 [https://doi.org/10.1186/s13014-015-0476-7] PMID: 26268771 PMCID: 4554300

54. Ruiz R, Strasser-Weippl K, and Touya D, et al (2017) Improving access to high-cost cancer drugs in Latin America: Much to be done Cancer 123(8) 1313-1323 https://doi.org/10.1002/cncr.30549

55. Senkus E, Gomez H, and Dirix L, et al (2014) Attitudes of young patients with breast cancer toward fertility loss related to adjuvant systemic therapies. EORTC study 10002 BIG 3-98 Psycho-Oncology 23(2) 173-182 [https://doi.org/10.1002/pon.3384]

56. Sparano JA, Gray RJ, and Makower DF, et al (2015) Prospective Validation of a 21-Gene Expression Assay in Breast Cancer $N$ Engl J Med 373(21) 2005-2014 https://doi.org/10.1056/NEJMoa1510764 PMID: 26412349 PMCID: 4701034

57. Sharma K, Costas A, and Shulman LN, et al (2012) A systematic review of barriers to breast cancer care in developing countries resulting in delayed patient presentation Journal of Oncology $121873 \mathrm{https} / / / \mathrm{doi} .0 \mathrm{rg} / 10.1155 / 2012 / 121873$ PMCID: 3432397

58. Stitzenberg KB and Meropol NJ (2010) Trends in centralization of cancer surgery Annals of Surgical Oncology 17(11) 2824-2831 [https://doi.org/10.1245/s10434-010-1159-0] PMID: 20559740

59. Tan DSW, Mok TSK, and Rebbeck TR (2016) Cancer genomics: diversity and disparity across ethnicity and geography $J$ Clin Oncol: Offic J Amer Soc Clin Oncol 34(1) 91-101 [https://doi.org/10.1200/JCO.2015.62.0096]

60. The Economist Intelligence Unit (2017) Control del cáncer, acceso y desigualdad en América Latina: Una historia de luces y sombras [https://eiuperspectives.com/sites/default/files/images/Cancer_control access_and_inequality in_Latin_America_SPANISH.pdf]

61. Torres Á, Oliver J, and Frecha C, et al (2017) Cancer genomic resources and present needs in the Latin American Region Public Health Genomics 20(3) 194-201 [https://doi.org/10.1159/000479291] PMID: 28848219

62. Tryfonidis K, Senkus E, and Cardoso M, et al (2015) Management of locally advanced breast cancer-perspectives and future directions Nature Reviews Clinical Oncology 12(3) 147-162 [https://doi.org/10.1038/hrclinonc.2015.13]

63. Valencia O, Lopes G, and Sánchez P, et al (2017) Incidence and prevalence of cancer in Colombia: the methodology used matters J Global Oncol 4 1-7 [https://doi.org/10.1200/JGO.17.00008]

64. Vallejos C (2013) National plan for prevention, early detection, and cancer control in Peru American Society of Clinical Oncology Educational Book American Society of Clinical Oncology Meeting [https://doi.org/10.1200/EdBook_AM.2013.33.e245]

65. Vidaurre T, Santos C, and Gómez H, et al (2017) The implementation of the plan esperanza and response to the imPACT Review The Lancet Oncol 18(10) e595-e606 [https://doi.org/10.1016/S1470-2045(17)30598-3] PMID: 28971826

66. Villarreal-Garza C, Aguila C, and Magallanes-Hoyos, et al (2013) Breast cancer in young women in Latin America: an unmet, growing burden The Oncologist 18(12) 1298-1306 [https://doi.org/10.1634/theoncologist.2013-0321] PMID: 24277771 PMCID: $\underline{3868424}$

67. Villarreal-Garza C, Martinez-Cannon BA, and Platas A, et al (2017) Fertility concerns among breast cancer patients in Mexico Breast Edinburgh Scotland 33 71-75 [https://doi.org/10.1016/j.breast.2017.02.010]

68. Welch HG, Prorok PC, and O'Malley AJ, et al (2016) Tumor Size, Overdiagnosis, and Mammography Screening Effectiveness $N$ Engl J Med 375(15) 1438-1447 https://doi.org/10.1056/NEJMoa1600249 PMID: 27732805

69. WHO (2017) WHO Model Lists of Essential Medicines 20th ed [http://www.who.int/medicines/publications/essentialmedicines/en/] accessed date 10/9/18

70. Yábar A, Meléndez R, and Muñoz S, et al (2017) Effect of Ki-67 assessment in the distribution of breast cancer subtypes: Evaluation in a cohort of Latin American patients Molec and Clin Oncol 6(4) 503-509 [https://doi.org/10.3892/mco.2017.1185] https://doi. org/10.3892/mco.2017.1185 